\title{
Life-threatening Epstein-Barr virus (EBV)-related hepatitis in a renal transplant patient
}

\author{
Authors: Faisal Rehman, ${ }^{\mathrm{A}}$ Yahya Makkeyah, ${ }^{\mathrm{A}}$ Abdul-Aema Buraq, ${ }^{\mathrm{A}}$ Georgina Aldous ${ }^{\mathrm{A}}$ and Sohail Ahmad ${ }^{\mathrm{A}}$
}

\section{Case presentation}

We report a case of Epstein-Barr virus (EBV)-related hepatitis in a young renal transplant patient. He developed end-stage renal failure in 2011 secondary to hypertension. He was EBV-negative and received an EBV-positive kidney from his mother in 2012. He received standard immune suppression with basiliximab followed by prednisolone, tacrolimus and mycophenolate mofetil (MMF). His post-transplant course was uneventful.

In August 2015 he developed mildly raised alanine aminotransaminase (ALT) of 93 IU/L (5-41). His doxycycline was stopped (recently started due to acne) and his ALT improved to $59 \mathrm{IU} / \mathrm{L}$ in December 2017. An EBV viral load of 253,858 IU/mL (5.4 log) was detected. A staging computed tomography (CT) was negative for post-transplant lymphoproliferative disorder (PTLD) and his MMF was halved to $250 \mathrm{mg}$ twice daily. He had a further rise in ALT and EBV titres and had a liver biopsy in April 2018, showing acute EBVrelated hepatitis. At this stage his MMF was stopped and he was given a trial of oral valgancyclovir, but it made no difference in 2 weeks of treatment.

In July 2018, he had a relentless rise in EBV viral load to $>2,000,000 \mathrm{IU} / \mathrm{mL}(6.35 \mathrm{log})$ and acute liver failure (bilirubin $176 \mu \mathrm{mol} / \mathrm{L}$, ALT $523 \mathrm{IU} / \mathrm{L}$ and alkaline phosphatase (ALP) 939 $\mathrm{IU} / \mathrm{L})$. His tacrolimus was stopped and prednisolone increased to $20 \mathrm{mg}$ once daily. A repeat CT and another liver biopsy did not show evidence of PTLD, but confirmed florid hepatitis due to EBV. He was negative for hepatitis A, B, C, E, adenovirus, HIV and cytomegalovirus.

At this stage he developed transplant dysfunction, probably secondary to hepatorenal syndrome or rejection. We did not perform a renal transplant biopsy as in case of rejection we were unable to increase his immune suppression due to florid EBV viraemia. He became anuric and dialysis dependent. EBV mainly infects B cells, therefore we treated him with four doses of anti-CD20 monoclonal antibody (rituximab) at $375 \mathrm{mg} / \mathrm{m}^{2}$. His liver functions recovered, his transplanted kidney began to function and he stopped dialysis after 7 weeks. At this stage he was commenced on low-dose tacrolimus, aiming for a level between 3 and $5 \mu \mathrm{g} / \mathrm{L}$.
In January 2019 his EBV titres went up again to 938,000 IU/mL with increases in ALT, ALP and gammaglutamyl transferase (GGT). Another CT and a positron emission tomography (PET) did not show evidence of PTLD. Therefore, he was given only one dose of rituximab. This has led to reduction in EBV viral load and normalisation of liver function tests.

This is a first report of EBV-related acute hepatitis in a renal transplant recipient. Acute hepatitis in the context of EBV infection is usually a self-limiting illness; however, this case was complicated by the need for immune suppression for maintaining renal transplant function. B-cell lysis with rituximab leads to a significant reduction in EBV viral load and may have a preventive role in future development of PTLD.

\section{Conflicts of interest}

None declared. 